\title{
COASTAL TRANSPORT INTEGRATED SYSTEM IN THE AEGEAN SEA ISLANDS: FRAMEWORK, METHODOLOGY, DATA ISSUES AND PRELIMINARY RESULTS
}

\author{
D. N. Pantazis, P. Stratakis, C. Karathanasis, E. Gkadolou, V. Pagounis, K. Chronis, M. Gatsiou, F. Moumouri-Fragkou and P. \\ Tsekos
}

Research Group SOCRATES (Society for Organizations, Cartography, Remote sensing and Applications using Technology on Earth and Space), Surveying Engineering Department, School of Technological Applications, Technological Educational Institution (TEI), Athens, Greece

KEY WORDS: costal transport information system, movement of people modelling

\begin{abstract}
:
Greece has more than one hundred inhabited islands, the majority of them are geographically scattered in small distances in the Aegean Sea. The Aegean Sea suffers systematically from two major issues. First, many islands are not served quite frequently with the continent or other islands' major ports. It is a situation rather problematic for the habitants of the islands who wish to travel, for the patients in need to be transferred to metropolitan hospitals, for the goods transport from and to islands. Second, there is a crucial issue in the Aegean Sea regarding the so-called "thin lines". Governments spend every year tens of million euros in subsidies in order to sustain the thin lines. Our aim is the development of an integrated and holistic spatial information system to effectively design coastal transportation lines to combat the above mentioned problems. This paper will present the project framework, the methodology followed, data issues and preliminary results.
\end{abstract}

\section{INTRODUCTION}

The aim of this paper is to present the research project "Coastal Transport Integrated System in the Aegean Sea Islands" and to summarize the preliminary results. The research project was one of the 237 proposals (out of the 643 that have been submitted) that have been selected (by foreigners experts/evaluators only) for funding by the European Union (European Social Fund) and Greek national resources under the framework of the "Archimedes III: Funding of Research Groups in TEI of Athens" project of the "Education \& Lifelong Learning" Operational Programme. The project started on March 2012 and will be finished on November 2014 .

This paper consists of five sections. The second section presents the framework and the proposal objectives. The third section discuss the methodology of the project, the forth the preliminary results and the fifth the conclusions.

\section{FRAMEWORK, CONCEPT, AND PROPOSAL'S OBJECTIVES}

\subsection{The context and policy issues}

Coastal transport in Greece is a network of mainland-to-island, island-to-island and mainland-to-mainland connections that concern the transportation of passengers, vehicles and goods. It is a very complex network of coastal transport lines, structured into thirty four main lines. Shipping companies cover the transport needs of the islands, with a fleet of ships of all types, carrying approximately thirty million passengers and seven million vehicles per year. Until the end of 2009, the domestic coastal transport was operating by one hundred seventy large and small ferries on average of which only a few serviced the thin lines. A "thin" line is a transport line to/from an island without business interest and low passenger traffic. Some of these coastal transport lines have been entirely subsidized by Greek governments. It is estimated that in Aegean Sea there are more than seventeen thin lines. During 2008-2009 these subsidies increased immensely and surpassed the amount of seventy million Euros. By 2010, the cost was estimated to reach the amount of one hundred million Euros.

The thin lines problem is linked with macroeconomic and microeconomic issues. At a microeconomic scale the issue of thin lines is very crucial. The state due to EU legislative has the obligation to finance the shipping companies to conduct particular itinerary to thin lines otherwise such itinerary is hardly viable economically. However, although there are subsidies, the shipping companies deny operating on certain thin lines. On the other hand, it is argued that the Greek government systematically lacks to fulfill its obligation in subsidies (subsidized coastal transport lines) resulting to their interruption. As a consequence, particular islands are left without coastal transport which negatively affects local economy and quality of life. This uncertainty is a major problem for the habitants of small islands and is getting bigger because according to the Greek law, shipping companies request to make itineraries only to lines with business interest. Nevertheless, even profitable lines are hardly viable during all the year. The majority of them are viable only in summer season and during the winter period are considered as thin lines. This increases the problem of thin lines. At the end of 2010, six important thin lines were not served regularly because there was not any interest by the shipping companies.

Policy issues play a crucial role in order to provide a sustainable coastal transport. A sustainable coastal transport system should be at least ensure: adequate itineraries coverage, constant passengers and goods transportation, quality services provision, retaining of the cost in reasonable levels, support to the economic activities, growth of local tourism and fair competition. Actually, the Greek maritime law does not adequately implemented and a lack of transparency has immense impact in coastal transport policies. During 2008 until 2010, the Greek competition committee reported that fourteen shipping companies developed "cartel" in order to control the ticket pricing policy. In simple words, when there was a tender announcement from the ministry of merchant shipping regarding the operation of thin lines, the shipping companies 
were in communication in order to bid at a fixed-predetermined cost or to bid in rotation.

As previously mentioned, such practices apart from establishing distortion of competition and corruption of the system of state tendering, they have resulted to the surcharge of Greek state with the amount of hundreds of million euros. Also, crucial is to mention-according to the press-that the consumers have been surcharged as well by the harmonised shipping companies' pricing policy on tickets. In addition to the above, during 20062008 the shipping companies have been accused for coordinating efforts to similarly adjust prices to any increase of the fuel cost. That is, the shipping companies were in agreement in case of increased energy prices to pass the surcharge on the tickets at the same amount.

\subsection{The proposal's framework}

The planning of the ships departure, especially during summer, is in accordance with the following criteria:

a) The departure from the mainland port (if possible) to be within a "commercial time".

b) The departure from the port of arrival to be in time in order to minimize the delay.

All the islands in relation to coastal transport face various problems which include:

1. Increased transportation costs due to distance, lack of natural resources and dependence on imported raw materials.

2. Insufficient infrastructure of ports that do not meet the safety standards compounded by poor management of financial resources for the construction of secured port infrastructure. In addition, Greece has been accused by the EU court for not implementing the directive 2000/59 regarding the development of reception stations for ship residues in all major ports.

3. Shallow coastline.

4. Strongly dependence from weather conditions. The port authorities have the right to issue for safety reasons, shipping prohibitions due to bad weather conditions.

\subsection{Proposal objectives}

Although many tools have been used for the optimal design of coastal transport (Geographic Information Systems-GIS, Data Base Management Systems - DBMS, transportation software, statistical tools) so far there has not been any integrated platform that could be used as a virtual reality tool, helping for the optimal design of such a complex system. Our aim is the creation of a tool based on an integrated and holistic spatial information system to effectively design coastal transport lines, using specific concepts of the "sales man" problem (and Graph Theory) and Game theory. We will take into account the constraints of the reality and the actual possibilities.

The objectives proposed system are:

a) To improve the quality of coastal transport lines.

b) To provide solutions for the problematic issue of "thin" lines.

c) To constitute a powerful tool of decision making in maritime transport policy to be used specially from the State and the local authorities as well

d) To allow customization of all factors of the problem (the costs, the need of inter-island communication, the ability of itineraries with response, the attractiveness of the solution for the ferry companies, the need for quality of coastal transport of the residents, the available funds, the current annual subsidies, etc.), offering a virtual reality platform in which the solutions of coastal transport could be developed and tested. This system will be designed as country and place independent so that to be able to stand alone for other coastal transport systems which they may have different structural parameters and problems than the Greek one. The output of the system will not be something that must be done but rather something which is possible to be done. Such a system does not actually exist.

The islands' isolation leads to underdevelopment and economic decline. The island residents demand to have access to mainland and other islands on a frequent basis, with safe and modern ships, cheap fares, discounts for the vulnerable groups of society, and improvement of port infrastructure in order to accommodate large ferries. It is obvious that a re-design of the coastal transport system in the Aegean Sea is needed.

The decision making of the proposal system should be take into account the demands of all who are involved. For analysis purposes we consider four groups as players for the system: the residents of the islands, the visitors / tourists, the shipping companies and the State / competent authorities. The quality of the decision making stage requires all the players to be satisfied. Therefore it is worthwhile to codify the needs / demands of the players.

The resident desire: to be sure that he has a reliable and modern transportation system with a reasonable transportation cost; to have as many as possible direct connections; to have the availability of alternative itineraries; to use in addition other transportation types; to make interconnections with islands in proximity; to have adequate itineraries during winter season; to ensure emergency situations (medical transports).

The visitor desire: to be sure that he has a reliable and modern transportation system with a reasonable transportation cost; to have the availability of alternative itineraries; to use in addition other transportation types; to make interconnections with islands in proximity; to have adequate itineraries during winter season; to ensure emergency situations (medical transports); to be aware of available routes per each port; to have the option of stay elongation.

The shipping company aspires: to exist a clear maritime national policy; to exist a stable institutional operation frame; to be improved infrastructures; ports and harbours to meet maritime standards; to exist a fair subsidize system; to keep the cost decline; to eliminate distortions of competitions.

The proposed system-tool will offer the virtual platform for this by focusing on the two main problematic issues:

1. The coastal connection of Aegean islands with the port of Piraeus and/or Rafina and/or Thessaloniki.

2. The Inter-island connections.

The problematic connection may concern different islands according to the season of the year. Some major problems of coastal connection concerns the islands of: Sikinos, Folegandros, Ai Stratis, Anafi, Thirasia, Karpathos, Chalki, Limnos, Samos, Chios, Shinousa, Patmos, Kithnos, Serifos, etc. Below are specific "hypotheses" to be analysed and tested by the proposed system:

1. Servicing of small islands with inter-island connection and transfer to metropolitan ports.

2. The coastal connections of all metropolitan island ports with the main port of Piraeus, the mainland of Greece and between 
them throughout the year should rely on the basis of actual needs.

3. It is important is to connect central Aegean islands with the port of Thessaloniki, given that many island residents are students in Thessaloniki and there is a systematic need to travel during summer vacation, Christmas and Easter time.

4. The specification of ticket pricing should rely on a thorough feasibility study that may ensure the sustainability of the coastal transport lines.

5. Tourism development in a great number of islands would be realised under the development of inter- insular coastal communication.

Some of the forecasting system output (besides the re-planning of optimal coastal transport lines) will be:

- A distribution method of forecasting passengers' movement (traffic) per port.

- Thematic maps of number of passengers per time periods, number of boarding per port, etc.

- Accessible information for any coastal transport line.

- Coastal transport line maps.

- Representation of travel duration according to the ship/ transfers.

- Estimation of optimum route with transfer from island to island/mainland to island/ island to mainland/ mainland to mainland/ or multiple islands itinerary.

- Map of the coastal transport line of a single ticket that may allow transfer from one ship to the other without surcharge including combined coastal transport (e.g. from one island to another and to mainland).

- Process allowing any user to receive information on how will get to an island from anywhere.

- A virtual platform in which all involved actors (local authorities, ministries, shipping companies, etc) could discuss for readjusting the organisation of coastal transport network and reforming it in order to improve it.

\section{METHODOLOGY}

\subsection{System development methodology}

The methodology to be used for the problem analysis stems from the adjusted "salesman" problem and also the game theory. For the system development, new terms will be used such as "isolated islands", "metropolitan islands", "in-between islands", "main coastal transport lines", "secondary routes", "stations of re-embarkation" etc.

For the development of the system itself, we adopt an original theoretical model that it has been successfully implemented internationally, the MECOSIG GIS design method (Pantazis and Donnay, 1996). We also draw from the classic Information Systems design and development phases, using prototype development from the very beginning.

\subsection{The problem analysis - the system requirements}

The coastal transport problem in the Aegean Sea is very complex and multivariable. It integrates technical issues regarding infrastructure, but also institutional, regulatory and strategic issues. There are different solutions for goods and passengers in different periods of the year due to the number of passengers and the volume of goods to be transferred by different kind of ships. To our knowledge so far there has not been any "tool" that would help to solve this kind of problem (optimal design of coastal transport network). It can be generally described with the classic problem of salesman, a theory first formulated as a mathematical problem in 1930 and it is one of the most intensively studied problems in optimization. It is used as a benchmark for many optimization methods. Given a collection of (a) cities/ports/ harbours etc. and (b) the cost of travel between each pair of them, the travelling salesman problem (TSP) is to find the cheapest way of visiting all the cities and return to the starting point.

In the standard version of the problem, the travel costs are symmetric in the sense that travelling from port $\mathrm{X}$ to port $\mathrm{Y}$ costs just as much as travelling from $Y$ to $X$. In our case a) the latter does not apply, b) the salesman does not wish to visit all the customers, c) the salesman visits some customers only in specific periods through the year, d) the salesman needs different transportation means to reach every customer, e) the salesman agrees to visit some customers if they pay a specific price, f) some salesmen wish to collaborate with other salesmen or wish not etc.

Elements of Game theory will be also used and integrated in our conceptual framework. Game theory attempts to mathematically capture behaviour in strategic situations, or games, in which an individual's success in making choices depends on the choices of others. In our case the game is the optimal design of a coastal transport network. While initially game theory was developed to analyze competitions in which one individual does better at another's expense (zero sum games), it has been expanded to treat a wide class of interactions, which are classified according to several criteria. Traditional applications of game theory attempt to find equilibrium in these games. In an equilibrium, each player of the game has adopted a strategy that they are unlikely to change.

Games can have several features; a few of the most common which are pertinent to our research proposal are listed here:

- Number of players: Each person who makes a choice in a game or who receives a payoff from the outcome of those choices is a player.

- Strategies per player: In a game each player chooses from a set of possible actions, known as strategies.

- Number of pure strategy Nash equilibriums: A Nash equilibrium is a set of strategies which represents mutual best responses to the other strategies. In other words, if every player is playing their part of a Nash equilibrium, no player has an incentive to unilaterally change his or her strategy. Considering only situations where players play a single strategy without randomizing (a pure strategy) a game can have any number of Nash equilibriums.

- Sequential game: A game is sequential if one player performs her/his actions after another; otherwise the game is a simultaneous move game.

- Perfect information: A game has perfect information if it is a sequential game and every player knows the strategies chosen by the players who preceded them.

- Constant sum: A game is constant sum if the sum of the payoffs to every player is the same for every set of strategies. In these games one player gains if and only if another player loses.

There will be also an effort to use, considering the multivariability of the problem, rules and concepts from the war game Kriegspiel, of Debord, based on the military theory of Carl Von Clausewitz. Our system is under a continuous change because of the constant modifications of the parameters that it is composed and influenced (number of passengers, wintertouristic period, weather conditions, economic situation, 
infrastructure, types of ships, needs, etc.). The aim of the system that will be proposed is to achieve a "balance" between needs and capacities, through the frame of a process which some approaches are better than others but without concluding to an optimum solution. As in Kriegspiel the "solution" to the problem of coastal transport will be achieved through a series of compromises where the "players" decision (local authorities, passengers, shipping companies, government actors, etc.) should rely on "contradictory necessities".

\subsection{The system requirements}

The system will be based on a GIS software in combination with specific transportation analysis software (for the creation and maintenance of transportation network) and add-on traffic management applications in the GIS platform taking into account the previous concepts from the problem analysis.

The problem analysis and solution/ system design will be based on an innovative approach combining network (vector) analysis and spatial analysis based on raster surfaces (e.g. representing the cost). Coastal transport networks will be created from scratch and /or using existing data. These networks will be stored in a geodatabase using a custom transportation data model based to the previous analysis. The data model will allow maintaining all aspects of the coastlines transport networks such as one way -two way rules, inter-island transport lines configurations, intersection attributes and geometry, passengers, cars, trucks or goods transport and other modes and schedules. Relationships between the coastline networks (e.g. interconnections between islands, islands and continent etc.) will be automatically managed enabling true multimodal networks. For example, if a user removes a small islands interconnection, they are prompted to ask how to resolve the impact on the coastline network: re-route another ship itinerary line or to create another coastline.

\section{PRELIMINARY RESULTS}

\subsection{Analysis current situation}

The geographical configuration of Greece is characterized by an extensive coastline which is $14,854 \mathrm{~km}$ and an insular complex with more than 3,500 islands. In this coastline there are more than 700 harbours and bays, more than 400 ports (small, medium, major) and hundreds of coastal navigation lines, served by dozens of maritime companies. These islands constitute the $19 \%$ of the Greek territory; the 124 have residents which are the $14 \%$ of the country's total population and 92 islands demand regular coastal connection with mainland.

The traffic of passengers is characterized by:

a. strong seasonality (with an average relationship summer : winter around 2:1). It is worth mentioning that the level of service is significantly reduced and the discontinuity of the connections between the islands becomes worse during the winter.

b. strong spatial heterogeneity. More specifically, in the network of the Aegean traffic which is the $70 \%$ of all passengers of coastal traffic, the $45 \%$ of total passenger traffic in the network takes place in the complex of Cyclades, $25 \%$ in Crete, the $15 \%$ in Dodecanese and the $15 \%$ in North Aegean. The network of Aegean is based in the port of Piraeus which is the departure point of $35 \%$ of total passengers' traffic. It is also the starting point of 10 main ferry routes, including those of the Saronic Gulf.

Currently, the coastal transport system in the Aegean Sea is unfortunately directed to the perception that it is a matter of ships management rather than of an integrated coastal transport system for the islands. As a consequence, and in addition to the previous policy description, there are two logics in conflict within the frame of Aegean Sea coastal transport. First, is the logic of public goods, which requires the continuing provision of transport services, and second is the logic of the economic viability of a service.

Coastal transport in the Aegean Sea therefore, suffers systematically by two major problems:

- First, many islands are not served - especially during the winter period- quite frequently with the continent or other islands' major ports. It is a situation rather problematic for the habitants and visitors of the islands who wish to travel, for the patients who are in need to be transferred to metropolitan hospitals and for the goods transport from and to the islands.

- Second, there is a crucial issue in the Aegean Sea regarding the so-called thin lines, previously analyzed. Unfortunately the above mentioned problems are so far unresolved.

In addition to the detailed analysis of the current situation concerning the process of costal lines decisions and implementation, we analyzing the Greek Code of Marine Law (which defines «coastal» shipping as the transfer of passengers and cargo between Greek ports), by identifying all articles, relative to proposed systems functions. We mention that there has been a drastic change in the Greek maritime legislation system the last 10 years with the law 2932/01, which has implemented the 3577/1992 Regulation of E.U: "Council Regulation (EEC) No 3577/92 applying the principle of freedom to provide services to maritime transport within Member States (maritime cabotage)".

\subsection{Literature review}

The literature review shows that some efforts have been made in order to incorporate the use of Geographical Information Systems in sea transport systems. The main efforts include a Marine GIS with 3D applications for navigation in ports (Gold et al, 2004), an adaptive GIS for maritime navigation (Carswell, and Tezuka, 2006), applications for tourism activities (Dragan et al, 2002). Moreover, models for monitoring real-time traffic, e.g. through the Automatic Identification System (AIS) which attempts to prevent delays in schedules have been developed (Claramunt et al, 2007), applications of Web-GIS marine systems for research activities (Kulawiak et al, 2010; Lam and Yip, 2008) and development of intelligent Transportation Maritime Systems (Pietrzykowski, Z., 2011).

Nevertheless, the analysis has highlighted the lack of an integrated spatial information system for the effective planning for coastal lines (which is the objective of our research project). The need to develop a system that will have the ability to plan and schedule the optimum routes in islands in the Aegean Sea, given the economic situation in Greece. Moreover, the proposed system which is a virtual platform with related tools can be used in any similar situation (other islands environments). 


\subsection{Initial requirements}

The system's functions will use spatial databases containing necessary spatial data (such as ports, islands, airports, hospitals, coastal lines etc.) related and integrated with other data (alphanumerical, multimedia) in order to take into account on the strategic decision processes, supported by the system.

Basic and advanced systems requirements include: a) identification and visualization of past, current and future locations of coastal lines, b) the possibility of coastal lines design using different kind of criteria (time, specific connections, shorter path), c) the possibility of various maps creation and visualization such as: i) digital and paper maps representing e.g. the coastal lines, the ports and the types of ships, ii) thematic maps based on the islands and coastal lines characteristics such as: island populations, island tourists number, frequency of coastal lines, etc., iii) animated maps, d) capabilities for monitoring, evaluating and analyzing coastal transport lines and relative infrastructure facilities (e.g. Ports).

System will support and propose possible solutions for coastal lines design with their respective advantages and disadvantages combining the graph theory and Games theory and related both with spatial and other data. Moreover, the system will have capabilities of storage and visualization of all the necessary data, which could be opened and updated simultaneously bringing a synchronized overview of the current situation.

The implementation of the system will be guided by international standards and models. The problem analysis and system design will be based on an innovative approach combining network (vector) analysis and spatial analysis of raster surfaces (e.g. representing the cost).

\subsection{Data collection}

The data collection have been performed with: a) Request to the competent institution, communication and/or meeting with an official of the institution, b) web search and c) field survey. Data collection has been finished and includes different categories such as descriptive, spatial, cartographic, etc.

The descriptive data include:

- Ports (name, location, type)-Main and secondary lines for 2010-2013 (name, ship, type, shipping company, frequency, statistics)- Shipping companies (name, communication data)Transport routes- Ships (name, type)- Passengers statistics for2007-2008, 2008-2009, 2009-2010 and 2010-2011Airports- Hospitals in the islands- Population data for census 2001-2011- Legislation- Data from field trip

The spatial data include:

- Coast line for all the islands - Administrative boundaries -

Location of ports in Greece- Location of airports Greece

Cartographic data include:

- Maps from Hellenic Military Geographical Service- Maps form Hellenic Navy Cartographic Service

The main problems that were faced during the data collection include: a) Fragmentation of information due to bureaucratic obstacles, b) Data overlap in different departments, c) Inappropriate data format, d) Lack of interoperability due to the lack of common standards in different sources, e) Discontinuous flow information as the cooperation between organizations for exchange of information is minimal.

Once the data have been put into place will be checked using the GIS, and the database (alphanumerical and spatial) of the system. Travel forecasting models and traffic simulations will also be developed to test proposed changes to infrastructure and policy. The GIS will display the spatial information in a geodatabase as a map. It will possible to edit geodatabase data, create maps, analyze data, and submit map-based queries. For example, the GIS it might be used to display and edit the geographic data in travel demand models, such as transportation networks and transportation analysis zones. All data could be edited within the GIS including the entire future coastal transport network.

\subsection{Future analysis}

In this actual phase the project focused on incorporating the great amount of existing data (alphanumerical, multimedia and spatial) and implementing it in a single environment based on GIS technology, working with a single databases on which data maintenance, cartographic printing and consultation will run simultaneously.

Coastal transport networks will be created from scratch and will be completed by using existing data. These networks will be stored in a geodatabase using a custom transportation data model based to the previous analysis. The data model will allow maintaining all aspects of the coast lines transport networks such as one way-two way rules, inter-island transport lines configurations, intersection attributes and geometry, passengers, cars, trucks or goods transport and other modes and schedules. Relationships between the coastline networks (e.g. interconnections between islands, islands and continent etc.) will be automatically managed enabling true multimodal networks.

Statistical processes results and graphic representations, are under preparation, and will give the picture of the actual situation simultaneously with the "hidden" possibilities that exist and the potential of new coastal lines. The necessary thematic maps that the system should be able to automatically or semi-automatically creates, have been determinated and the process of their creation is already starting. Conceptual data models and data dictionary are still in progress. The second stage of the project and is focused on database development, digitalisations and integration of information and development of custom functionalities in GIS software.

\section{CONCLUSIONS}

The proposed spatial information system for optimal design of coastal transport network, which will be the final deliverable of our research, could be used as a tool in any similar problem of coastal lines design. The potential users could be a) the government ministries that will use it as a maritime policy tool, b) the local authorities that will use it to analyze their needs, discover transport opportunities, and develop their proposals by taking into account the consequences (economic, social) of any proposed idea c) the shipping companies that will use it as an operational / business planning tool.

The creation of such a tool will help to improve the maritime policy actions of the Greek government. The actors stakeholders will also have a strategic tool at their disposal to 
conduct their moves more accurately. The local governments will also evaluate more precisely the costs and benefits of each demand to create new or to modify existing coastal transport lines.

It is known that the small islands face an acute problem in coastal connection not only with the big continental harbours but also with neighbouring islands. Even in the case of central transport lines, the rule during the winter is that itineraries are not fast and frequent. High cost grants for thin lines with doubtful however quality results are a well-known issue.

Such a holistic system will lead to the growth of regional tourism throughout the year, but also to the additional growth of trade between local societies. Economic growth may occur through the development of new small and medium size (SMEs) shipping companies that will serve the inter-island connections. The design of an optimal coastal transport system is expected to contribute in the essential and qualitative upgrade of coastal communication and service of islands of Aegean with mainland (Metropolitan continental harbours) but also with small and remote islands ("thin" lines). It will constitute a decision making tool for effective coastal transport policy based on actual needs but also taking into consideration the restrictions of reality.

It is evident that the proposed system is universal because it can be used in any other insular region with similar problems in coastal transport, capable at the same time to incorporate the particularities of the local settings.

\subsection{References}

Chlomoudis T. I. M. Lekakou, K. Panou, E. Papadimitriou, I. Syriopoulos E. Tzanis, 2007. Transport: Arteries of Life on Islands, edited by: ITA, Papazisis editions (in Greek)

Claramunt, C. , Devogele, T. , Fournier, S., Noyon, V. , Petit M. and Ray C., 2007. Maritime GIS: From Monitoring to Simulation Systems, in Information fusion and Geographic Information Systems, Lecture Notes in Geoinformation and Cartography, 2007, Part 1, pp. 34-44

Dragan, M. and Fernetti, M., 2002. Geographical Awareness for Modern Travellers: A GIS Application for Maritime Transportation in the Mediterranean Sea, In: Wright, D.J.; Earle, S., Undersea with GIS, ESRI Press: Redlands, pp. 230244.

Gold C., M. Chau, M. Dzieszko, and R. Goralski, 2004. The 'Marine GIS' - Dynamics GIS in Action, International Society for Photogrammetry and Remote Sensing Conference, Istanbul.

Gold, C. and Condal, A.,1995. A spatial data structure integrating GIS and simulation in a marine environment, Marine Geodesy, 18:3, pp. 213-228.

Kulawiak, M., Chybicki, A. and Moszynski, M., 2010. WebBased GIS as a Tool for Supporting Marine Research, Marine Geodesy, 33, pp. 135-153.

Lam, S.Y.-W., Yip, T.L., 2008. The role of geomatics engineering in establishing the marine in-formation system for maritime management, Maritime Policy and Management, 35 (1), pp. 53-60.
Pantazis, D., Donnay J.P. 1996. La conception de SIG, Méthode et formalisme, Hermès, Paris, 343 p.

Petit, M., Ray, C. and Claramunt, C., 2006. A Contextual Approach for the Development of GIS: Application to Maritime Navigation, in J.D. Carswell and T. Tezuka (Eds.): Web and wireless geographical information systems, Lecture Notes in Computer Science, 2006, Volume 4295/2006, Springer-Verlag Berlin Heidelberg, pp. 158-169.

Pietrzykowski, Z., 2011. Navigational decision support system as an element of intelligent transport systems, Zeszyty Naukowe 25(97), pp. 41-47.

\subsection{Acknowledgements}

This research has been co-funded by the European Union (European Social Fund) and Greek national resources under the framework of the "Archimedes III: Funding of Research Groups in TEI of Athens" project of the "Education \& Lifelong Learning" Operational Programme. 